\title{
Usability Testing Pada Aplikasi Zoom Dengan Menggunakan Metode Cognitive Walkthrough
}

\author{
Kartika Gianina Tileng \\ Universitas Ciputra Surabaya; UC Town, Citraland CBD Boulevard, 031-7451699 \\ ${ }^{3}$ Jurusan Sistem Informasi, Fakultas Teknologi Informasi, Surabaya \\ e-mail: kargia@ciputra.ac.id
}

\begin{abstract}
Abstrak
Pandemi Covid-19 yang terjadi di berbagai belahan dunia mengakibatkan banyak interaksi sosial dikurangi dan berbagai aktivitas dialihkan menjadi berbasis online. Salah satu dampak signifikan yang terjadi adalah perkuliahan yang diselenggarakan secara online. Guna mendukung perkuliahan secara online ini, ada berbagai tools teknologi yang digunakan untuk membantu proses online tersebut, salah satu diantaranya adalah aplikasi teleconference. Dalam perubahan metode offline menjadi online, ada banyak adaptasi aktivitas yang harus dilakukan oleh dosen maupun mahasiswa atau peserta didik lainnya dalam melakukan kegiatan perkuliahan dalam perguruan tinggi. Oleh sebab itu, penelitian ini bertujuan untuk melihat bagaimana proses adaptasi teknologi dalam pembelajaran online melihat semakin banyaknya aktivitas pembelajaran yang berbasis online, untuk kemudian merancangkan desain aplikasi yang dirasa sesuai dengan keperluan. Penelitian ini dilakukan dengan metode Cognitive Walkthrough, dengan menggunakan responden sebanyak 5 orang yang menjalani penugasan sesuai job desk dan perekaman layar, maka didapatlah kesimpulan bahwa penggunaan Zoom untuk 4 fitur utama sudah dapat dilakukan dengan baik, kesulitan hanya terjadi pada skenario kedua.
\end{abstract}

Kata kunci-Usability Testing, Cognitive Walkthrough, Zoom

\begin{abstract}
The Covid-19 pandemic that occurred in various parts of the world resulted in a reduction in social interactions and various activities being shifted to an online basis. One of the significant impacts that occurs is lectures that are held online. To support this online lecture, there are various technological tools that are used to assist the online process, one of which is the teleconference application. In changing the offline method to online, there are many adaptations of activities that must be carried out by lecturers and students or other students in carrying out lecture activities in higher education. Therefore, this study aims to see how the technology adaptation process in online learning sees the increasing number of onlinebased learning activities, to then design an application that is deemed appropriate. This research was conducted using the Cognitive Walkthrough method, using 5 respondents who were assigned according to work desks and screen recording, so it was found that the use of Zoom for 4 main features could be done well, difficulties only occurred in the second scenario.
\end{abstract}

Keywords - Usability Testing, Cognitive Walkthrough, Zoom 


\section{PENDAHULUAN}

Hadirnya pandemi Covid-19 yang terdeteksi sejak akhir tahun 2019 dan mulai mewabah di berbagai belahan dunia pada tahun 2020 termasuk Indonesia, membuat berbagai sektor mengalami pengaruh signifikan. Salah satu di antaranya adalah di bagian sektor pendidikan. Kegiatan proses pendidikan di Indonesia yang biasanya dijalankan dengan cara tatap muka langsung, mulai berubah seiring kebijakan dari pemerintah dalam menanggulangi kondisi yang diakibatkan oleh pandemi Covid- 19, dialihkan menjadi aktivitas tatap maya secara online. Dalam hal ini, ada banyak adaptasi aktivitas yang harus dilakukan oleh para dosen maupun mahasiswa dalam melakukan berbagai kegiatan perkuliahan dalam perguruan tinggi. Oleh sebab itu, dirasa penting untuk melihat bagaimana proses adaptasi teknologi yang digunakan sebagai tools, dalam perkuliahan online melihat keadaan yang semakin mengandalkan aktivitas online. Penggunaan platform teknologi teleconference dalam metode perkuliahan online semakin marak digunakan karena sangat membantu untuk menggantikan proses tatap muka yang biasanya dijalani. Oleh sebab itu, penting untuk mengamati bagaimana proses adaptasi oleh para peserta didik dalam menggunakan platform Zoom sebagai tools dalam kegiatan pembelajaran. Berdasarkan International Standarts Office dihasilkan dari penggunaan dan atau antisipasi penggunaan produk, sistem atau layanan. Sebuah produk dapat dikatakan baik jika memiliki kesesuaian antar fitur dengan kebutuhan penggunanya. Dalam user experience pengguna diharapkan dapat berinteraksi dengan sistem secara mudah dan efisien. [1] Metode yang dapat digunakan untuk menilai user experience adalah usability evaluation. Usability adalah suatu ukuran, dimana pengguna dapat mengakses fungsionalitas dari sebuah sistem dengan efektif, efisien dan memuaskan dalam mencapai tujuan tertentu. Pengukuran usability pada sebuah aplikasi sangat penting, karena dengan adanya pengukuran tersebut akan diketahui tingkat kemudahan suatu Aplikasi ketika digunakan [2]. Salah satu metode di dalam usability evaluation yang sering digunakan adalah cognitive walkthrough. Cognitive walkthrough merupakan metode evaluasi usability dimana satu atau lebih evaluator bekerja melalui serangkaian skenario tugas dan meminta sejumlah pertanyaan dari perspektif pengguna [3]. Cognitive walkthrough adalah sebuah metode evaluasi yang dapat memprediksi seberapa mudah seseorang mengerti terhadap tugas yang diberikan dalam menggunakan sistem berbasis komputer [4]. Metode ini mengharuskan evaluator mengamati apa yang dilakukan oleh pengguna saat melakukan skenario - skenario tugas yang diberikan sehingga evaluator dapat mengetahui apakah sistem mudah dimengerti atau tidak. Beberapa penelitian yang telah dilakukan menunjukkan bahwa pengujian Cognitive Walkthrough mampu mengidentifikasi kendala-kendala yang dihadapi pengguna ketika menggunakan sebuah antarmuka. Pengembangan antarmuka berdasarkan hasil pengujian tersebut mampu meningkatkan efektivitas penggunaan website. [5]

Adapun ruang lingkup untuk penelitian ini adalah:

1. 4 fitur utama Zoom yang diuji adalah 4 fitur yang dianggap paling sering digunakan dalam proses menjadi peserta pembelajaran yaitu:

a. Pertemuan rapat one-on-one.

b. Konferensi rapat grup video.

c. Screen sharing dan chat.

d. Fitur recording video call.

2. Responden penelitian meliputi 5 mahasiswa aktif pengguna Zoom.

3. Dalam pengujian terkait Usability ini, ada 2 unsur yang dicermati, yaitu efektivitas dan efisiensi.

a. Efektivitas berkaitan dengan tingkat penyelesaian skenario tugas.

b. Efisiensi berhubungan dengan jumlah waktu yang diperlukan untuk menyelesaikan dan jumlah kesalahan yang dilakukan pada saat menyelesaikan skenario tugas. 


\section{METODE PENELITIAN}

Uji Usability dengan metode Cognitive Walkthrough, terdiri dari 2 (dua) tahapan, yaitu tahan persiapan (preparation) dan tahap eksekusi (execution). Tahapan persiapan meliputi studi literature, mempelajari sistem yang akan diuji, menentukan responden dan menyusun skenario tugas yang harus dikerjakan oleh responden.

\subsection{Responden}

Responden penelitian ini adalah 5 mahasiswa aktif yang menggunakan Zoom baik dalam kegiatan pembelajaran secara langsung (kelas tatap maya) maupun secara tidak langsung (kerja kelompok). Teknik yang digunakan dalam menentukan sampel adalah simple random sampling dari populasi mahasiswa jurusan Sistem Informasi yang dianggap telah familiar dengan penggunaan teknologi. Menurut Nielsen (2012), jumlah peserta untuk pengujian ini adalah sebanyak 5 (lima) peserta.

\subsection{Skenario Tugas}

Untuk pembagian tugas dibagi ke dalam 4 kelompok dari fitur-fitur yang dianggap utama dalam penggunaan aplikasi Zoom seperti berikut ini:
a. Pertemuan rapat one-on-one.
b. Konferensi rapat grup video.
c. Screen sharing dan chat.
d. Fitur recording video call.

\subsubsection{Pertemuan rapat one-on-one.}

1. Meminta peserta membuat account baru di Zoom

2. Meminta peserta $\log$ in di Zoom

3. Meminta peserta untuk membuat sebuah meeting dan menyebarkan invitation ke salah satu sosial media (Tombol perisai dan Participant)

4. Meminta peserta untuk join meeting (diundang anggota lain)

5. Meminta peserta untuk leave meeting

Tabel 1. Skenario Uji Usability Dalam Pertemuan Rapat One-On-One

\begin{tabular}{|c|l|l|}
\hline ST & \multicolumn{1}{|c|}{ Tujuan } & Tahapan \\
\hline ST 1 & Meminta peserta membuat account baru di Zoom & 7 \\
\hline ST 2 & Meminta peserta log in di Zoom & 2 \\
\hline ST 3 & $\begin{array}{l}\text { Meminta peserta untuk membuat sebuah meeting dan menyebarkan } \\
\text { invitation ke salah satu sosial media (Menggunakan tombol Perisai } \\
\text { dan Participant) }\end{array}$ & 5 dan 6 \\
\hline ST 4 & $\begin{array}{l}\text { Meminta peserta untuk join meeting (diundang anggota lain) } \\
\text { ST 5 }\end{array}$ & 2 \\
\hline
\end{tabular}

Keterangan: Skenario Tugas $=$ ST 


\subsubsection{Konferensi rapat grup video}

1. Meminta peserta untuk menggunakan fitur mute, unmute, on cam dan off cam pada breakout room

2. Meminta peserta membuat breakout room

3. Meminta peserta Rename Participant

4. Meminta peserta untuk menjadikan anggota lain sebagai host

5. Meminta peserta untuk menjadikan anggota lain sebagai co-host

6. Meminta peserta untuk mengganti virtual background

7. Meminta peserta untuk memberikan reaction

Untuk tahapan-tahapan yang dalam setiap Skenario Tugas digambarkan dalam Tabel 2.

Tabel 2. Skenario Uji Usability Dalam Konferensi Rapat Grup Video

\begin{tabular}{|c|l|l|}
\hline ST & \multicolumn{1}{|c|}{ Tujuan } & \multicolumn{1}{|c|}{ Tahapan } \\
\hline ST 1 & $\begin{array}{l}\text { Meminta peserta untuk menggunakan } \\
\text { fitur mute, unmute, on cam dan off cam }\end{array}$ & $1,1,1,1$ \\
\hline ST 2 & $\begin{array}{l}\text { Meminta peserta membuat breakout } \\
\text { room }\end{array}$ & 4 \\
\hline ST 3 & Meminta peserta Rename Participant & 5 \\
\hline ST 4 & $\begin{array}{l}\text { Meminta peserta untuk menjadikan } \\
\text { anggota lain sebagai host }\end{array}$ & 4 \\
\hline ST 5 & $\begin{array}{l}\text { Meminta peserta untuk menjadikan } \\
\text { anggota lain sebagai co-host }\end{array}$ & 4 \\
\hline ST 6 & $\begin{array}{l}\text { Meminta peserta untuk mengganti } \\
\text { virtual background }\end{array}$ & 5 \\
\hline ST 7 & $\begin{array}{l}\text { Meminta peserta untuk memberikan } \\
\text { reaction }\end{array}$ & 2 \\
\hline
\end{tabular}

Keterangan: Skenario Tugas $=$ ST

\section{Screen sharing dan chat.}

a. Meminta peserta untuk melakukan chatting dengan peserta lain secara pribadi

b. Meminta peserta Melakukan share-screen file atau website.

Tabel 3. Screen Sharing dan Chat

\begin{tabular}{|c|l|c|}
\hline ST & \multicolumn{1}{|c|}{ Tujuan } & Tahapan \\
\hline ST 1 & $\begin{array}{l}\text { Meminta peserta untuk melakukan chatting } \\
\text { dengan peserta lain secara pribadi }\end{array}$ & 4 \\
\hline ST 2 & $\begin{array}{l}\text { Meminta peserta Melakukan share-screen } \\
\text { untukfile atau website }\end{array}$ & 2 \\
\hline
\end{tabular}

4. Fitur recording video call

a. Meminta peserta untuk start recording

b. Meminta peserta untuk stop recording 
c. Meminta peserta untuk mengecek dimana recording tersebut tersimpan.

Tabel 4. Fitur Recording Video Call

\begin{tabular}{|c|l|l|}
\hline ST & \multicolumn{1}{|c|}{ Tujuan } & Tahapan \\
\hline ST 1 & Meminta peserta untuk start recording & 1 \\
\hline ST 2 & Meminta peserta untuk stop recording & 1 \\
\hline ST 3 & $\begin{array}{l}\text { Meminta peserta untuk mengecek dimana } \\
\text { recording tersebut tersimpan }\end{array}$ & 1 \\
\hline
\end{tabular}

\section{HASIL DAN PEMBAHASAN}

Adapun hasil dari penelitian ini menunjukkan hasil seperti berikut ini pada setiap responden (User) untuk skenario Uji Usability dalam pertemuan rapat one-on-one ditunjukkan dalam Tabel 5.

Tabel 5. Hasil Skenario Untuk Pertemuan Rapat One-On-One

\begin{tabular}{|c|l|c|c|c|c|c|}
\hline ST & \multicolumn{1}{|c|}{ Tujuan } & User 1 & User 2 & User 3 & User 4 & User 5 \\
\hline ST 1 & $\begin{array}{l}\text { Meminta peserta membuat } \\
\text { account baru di Zoom }\end{array}$ & 7 & 7 & 7 & 7 & 7 \\
\hline ST 2 & Meminta peserta log in di Zoom & 2 & 2 & 2 & 2 & 2 \\
\hline ST 3 & $\begin{array}{l}\text { Meminta peserta untuk membuat } \\
\text { sebuah meeting dan menyebarkan } \\
\text { invitation ke salah satu sosial } \\
\text { media (Whatsapp atau Line) }\end{array}$ & 6 & 5 & 5 & 6 & 5 \\
\hline ST 4 & $\begin{array}{l}\text { Meminta peserta untuk join } \\
\text { meeting (diundang anggota lain) }\end{array}$ & 2 & 2 & 2 & 2 & 2 \\
\hline ST 5 & $\begin{array}{l}\text { Meminta peserta untuk leave } \\
\text { meeting }\end{array}$ & 2 & 2 & 2 & 2 & 2 \\
\hline
\end{tabular}

Dengan jumlah waktu penyelesaian skenario tugas yang ditunjukkan pada Tabel 6 di bawah ini. 
Tabel 6. Waktu Penyelesaian Skenario Tugas Untuk Pertemuan Rapat One-On-One (Dalam Detik)

\begin{tabular}{|l|l|l|l|l|l|l|}
\hline Responden & ST 1 & ST 2 & ST 3 & ST 4 & ST 5 & Rata-rata \\
\hline user 1 & 132 & 14 & 31 & 6 & 3 & 37.2 \\
\hline user 2 & 100 & 15 & 60 & 54 & 2 & 46.2 \\
\hline user 3 & 39 & 15 & 123 & 9 & 5 & 38.2 \\
\hline user 4 & 270 & 30 & 37 & 45 & 16 & 79.6 \\
\hline user 5 & 84 & 3 & 22 & 11 & 3 & 24.6 \\
\hline rata-rata & 125 & 15.4 & 54.6 & 25 & 5.8 & 45.16 \\
\hline max & 270 & 30 & 123 & 54 & 16 & \\
\hline min & 39 & 3 & 22 & 6 & 2 & \\
\hline
\end{tabular}

Adapun hasil dari penelitian ini menunjukkan hasil seperti berikut ini pada setiap responden (User) untuk skenario Uji Usability dalam konferensi rapat grup video ditunjukkan dalam Tabel 7.

Tabel 7. Hasil Skenario untuk Konferensi Rapat Grup Video

\begin{tabular}{|c|l|l|l|l|l|l|}
\hline ST & \multicolumn{1}{|c|}{ Tujuan } & User 1 & User 2 & User 3 & User 4 & User 5 \\
\hline ST 1 & $\begin{array}{l}\text { Meminta peserta untuk } \\
\text { menggunakan fitur mute, } \\
\text { unmute, on cam dan off cam }\end{array}$ & $1,1,1,1$ & $1,1,1,1$ & $1,1,1,1$ & $1,1,1,1$ & $1,1,1,1$ \\
\hline ST 2 & $\begin{array}{l}\text { Meminta peserta membuat } \\
\text { breakout room }\end{array}$ & 4 & 4 & $>4$ & $>4$ & 4 \\
\hline ST 3 & $\begin{array}{l}\text { Meminta peserta melakukan } \\
\text { rename } \\
\text { Participant }\end{array}$ & 4 & 4 & 4 & 4 & 4 \\
\hline ST 4 & $\begin{array}{l}\text { Meminta peserta untuk } \\
\text { menjadikan anggota lain } \\
\text { sebagai host }\end{array}$ & 4 & 4 & 4 & 4 & 4 \\
\hline ST 5 & $\begin{array}{l}\text { Meminta peserta untuk } \\
\text { menjadikan anggota lain } \\
\text { sebagai co-host }\end{array}$ & 4 & 4 & 4 & 4 & 4 \\
\hline ST 6 & $\begin{array}{l}\text { Meminta peserta untuk } \\
\text { mengganti background }\end{array}$ & 5 & 5 & 5 & 5 & 5 \\
\hline ST 7 & $\begin{array}{l}\text { Meminta peserta untuk } \\
\text { memberikan reaction }\end{array}$ & 2 & 2 & 2 & 2 & 2 \\
\hline
\end{tabular}


Keterangan : ST $=$ Skenario Tugas

Dengan jumlah waktu penyelesaian skenario tugas yang ditunjukkan pada Tabel 8 di bawah ini.

Tabel 8. Waktu Penyelesaian Skenario Tugas untuk Konferensi Rapat Grup Video (Dalam Detik)

\begin{tabular}{|l|l|l|l|l|l|l|l|l|}
\hline Responden & ST 1 & ST 2 & ST 3 & ST 4 & ST 5 & ST 6 & ST 7 & Rata-rata \\
\hline User 1 & 1 & 36 & 8 & 5 & 5 & 6 & 2 & 9 \\
\hline User 2 & 1 & 19 & 11 & 3 & 6 & 19 & 8 & 9.571429 \\
\hline User 3 & 1 & 202 & 14 & 9 & 7 & 10 & 3 & 35.14286 \\
\hline User 4 & 1 & 125 & 12 & 6 & 4 & 30 & 7 & 26.42857 \\
\hline User 5 & 1 & 44 & 11 & 6 & 7 & 5 & 7 & 11.57143 \\
\hline Rata-rata & 1 & 85.2 & 11.2 & 5.8 & 5.8 & 14 & 5.4 & 18.34286 \\
\hline Max & 1 & 202 & 14 & 9 & 7 & 30 & 8 & \\
\hline Min & 1 & 19 & 8 & 3 & 4 & 5 & 2 & \\
\hline
\end{tabular}

Adapun hasil dari penelitian ini menunjukkan hasil seperti berikut ini pada setiap responden (User) untuk skenario Uji Usability dalam screen sharing dan chat ditunjukkan dalam Tabel 9.

Tabel 9. Screen Sharing dan Chat

\begin{tabular}{|c|l|c|c|c|c|c|}
\hline ST & Tujuan & User 1 & User 2 & User 3 & User 4 & User 5 \\
\hline ST 1 & $\begin{array}{l}\text { Meminta peserta untuk melakukan } \\
\text { chatting dengan peserta lain secara } \\
\text { pribadi }\end{array}$ & 4 & 4 & 4 & 4 & 4 \\
\hline ST 2 & $\begin{array}{l}\text { Meminta peserta Melakukan share } \\
\text { screen untuk file atau website }\end{array}$ & 2 & 2 & 2 & 2 & 2 \\
\hline
\end{tabular}
bawah ini.

Dengan jumlah waktu penyelesaian skenario tugas yang ditunjukkan pada Tabel 8 di 
Tabel 10. Waktu Penyelesaian Skenario Tugas untuk Screen Sharing dan Chat (Dalam Detik)

\begin{tabular}{|l|l|l|l|}
\hline Responden & ST 1 & ST 2 & Rata-rata \\
\hline User 1 & 5 & 16 & 10.5 \\
\hline User 2 & 26 & 28 & 27 \\
\hline User 3 & 9 & 4 & 6.5 \\
\hline User 4 & 25 & 5 & 15 \\
\hline User 5 & 5 & 30 & 17.5 \\
\hline Rata-rata & 14 & 16.6 & 15.3 \\
\hline Max & 26 & 30 & \\
\hline Min & 5 & 4 & \\
\hline
\end{tabular}

Adapun hasil dari penelitian ini menunjukkan hasil seperti berikut ini pada setiap responden (User) untuk skenario Uji Usability dalam menu recording video call yang ditunjukkan dalam Tabel 11.

Tabel 11. Recording Video Call

\begin{tabular}{|l|l|l|l|l|l|l|}
\hline ST & Tujuan & User 1 & User 2 & User 3 & User 4 & User 5 \\
\hline ST 1 & $\begin{array}{l}\text { Meminta peserta untuk start } \\
\text { recording }\end{array}$ & 1 & 1 & $>1$ & 1 & 1 \\
\hline ST 2 & $\begin{array}{l}\text { Meminta peserta untuk stop } \\
\text { recording }\end{array}$ & 1 & 1 & 1 & 1 & 1 \\
\hline ST 3 & $\begin{array}{l}\text { Meminta peserta untuk mengecek } \\
\text { dimana recording tersebut } \\
\text { tersimpan }\end{array}$ & 1 & 1 & 1 & 1 & 1 \\
\hline
\end{tabular}

Keterangan: $\mathrm{ST}=$ Skenario Tugas

Adapun hasil dari penelitian ini menunjukkan hasil seperti berikut ini pada setiap responden (User) untuk skenario Uji Usability dalam fitur recording video call dalam Tabel 12. 
Tabel 12. Waktu Penyelesaian Skenario Tugas untuk Fitur Recording Video Call (Dalam Detik)

\begin{tabular}{|c|c|c|c|c|}
\hline Responden & ST 1 & ST 2 & ST 3 & Rata-rata \\
\hline User 1 & 8 & 3 & 5 & 5.333333 \\
\hline User 2 & 7 & 3 & 5 & 5 \\
\hline User 3 & 26 & 7 & 4 & 12.33333 \\
\hline User 4 & 3 & 2 & 4 & 3 \\
\hline User 5 & 3 & 2 & 4 & 3 \\
\hline Rata-rata & 9.4 & 3.4 & 4.4 & 5.733333 \\
\hline Max & 26 & 7 & 5 & \\
\hline Min & 3 & 2 & 4 & \\
\hline
\end{tabular}

\section{KESIMPULAN}

Hasil pengujian Usability Testing dengan metode Cognitive Walkthrough menunjukkan bahwa permasalahan yang dihadapi pengguna pada waktu menggunakan aplikasi Zoom hanya terdapat dalam pengujian skenario fitur utama ke-2 (Konferensi grup rapat video) yaitu dalam membuat breakout room (2 user) dan memberikan reaction (2 user). Dalam interview di akhir sesi perekaman layar, serta adanya masukan untuk menambahkan fitur file sharing dari pengajar saat menjelaskan sesuatu materi. Zoom telah memiliki fitur untuk berbagi obrolan, sehingga untuk keperluan pembelajaran dirasa akan semakin baik, jika dapat memberikan suatu layanan untuk file sharing, yang bisa terhubung ke cloud, sehingga peserta pembelajaran dapat berfokus pada 1 tampilan dan tidak harus membuka beberapa layar saat sedang mengikuti proses tatap maya.

\section{SARAN}

Penelitian selanjutnya dapat dilakukan setelah adanya desain ulang dengan memperhatikan dari rekomendasi yang diberikan pada penelitian ini. Selain itu, dapat juga dilakukan penelitian dalam metode Usability Testing yang lain dengan menggunakan kerangka lainnya seperti Heuristic Evaluation, dan lain sebagainya. 


\section{UCAPAN TERIMA KASIH}

Terima kasih kepada Universitas Ciputra atas dukungan dalam skema hibah untuk penelitian ini.

\section{DAFTAR PUSTAKA}

[1] Silvia Ayu Ardyani, Erly Krisnanik, S.Kom., MM, Ika Nurlaili I, S.Kom., M.Sc, 2020, Analisis User Experience dan Redesain Website My Permata Wisata Dengan Menggunakan Metode Cognitive Walkthrough, Fakultas Ilmu Komputer Universitas Pembangunan Nasional "Veteran" Jakarta.

[2] Mohamad Rahmatuloh, 2018, Pengukuran Usability Menggunakan Cognitive Walkthrough pada Aplikasi Tugas Akhir, Mei 2018.

[3] Revianda Amrullah Akbar, Hanifah Muslimah Az-Zahra, Komang Candra Brata, 2019, Evaluasi User Experience pada Game PUBG MOBILE Menggunakan Metode Cognitive Walkthrough, Jurnal Pengembangan Teknologi Informasi dan Ilmu Komputer, Vol. 3, No. 2, Februari 2019, hlm. 1660-1668.

[4] Blackmon, M. H. 2004, Cognitive Walkthrough. In W. S. Bainbridge (Ed.), Encyclopedia of Human Computer Interaction, Great Barrington, MA: Berkshire Publishing Group.

[5] Ira Maryati, Firman Ardiansyah, Wisnu Ananta Kusuma. 2014, Pengujian Cognitive Walkthrough Antarmuka Perpustakaan Digital (E-LIBRARY) Pusat Dokumentasi dan Informasi Ilmiah - LIPI (PDII-LIPI), Pusat Dokumentasi dan Informasi Ilmiah-Lembaga Ilmu Pengetahuan Indonesia. 